\title{
Desempenho do escore prognóstico de Glasgow no câncer gástrico
}

\author{
Performance of the Glasgow prognostic score in gastric cancer
}

Higino Felipe Figueiredo ${ }^{1}$ (D), Rosane Dias Da Rosa ${ }^{1}$ (D), Luciana Botinelly Mendonça Fujimoto ${ }^{2}$, Renata Motoki Amorim Pereira ${ }^{2}$ (D), Fernando Luiz Westphal ${ }^{1}$ (D), Gerson Suguiyama Nakajima ${ }^{1}$ (1)

\begin{abstract}
RESUMO
A resposta inflamatória sistêmica e o déficit nutricional são características frequentes nos pacientes com câncer e o escore prognóstico de Glasgow tem se mostrado excelente valor prognóstico no câncer gastresofágico e ferramenta validada na avaliação clínica de pacientes com câncer. Assim, o presente estudo teve como objetivo analisar a associação do escore prognóstico de Glasgow com sobrevida de pacientes portadores de carcinoma gástrico, através de revisão sistemática e meta-análise. Foi seguida a metodologia Preferred Reporting Items for Systematic Reviews and Meta-Analyses-PRISMA, com pesquisa nas plataformas Medline, Web of Science e SCOPUS, utilizando descritores apropriados. Foram incluídos estudos clínicos e observacionais, publicados antes de 30.09.2017 e sem restrição de linguagem. Os critérios de inclusão foram a utilização do escore prognóstico de Glasgow como fator prognóstico em pacientes portadores de diagnóstico histológico de carcinoma gástrico; com idade superior a 18 anos; submetidos à quimioterapia, radioterapia ou cirurgia; com dosagem de Proteína C Reativa e albumina no pré-tratamento; e com dados referentes à sobrevida durante o estudo. A qualidade dos estudos foi avaliada com a Escala de NewcastleOttawa e o risco de viés com ferramenta da Cochrane Collaboration. Hazard-Ratio e Intervalo de Confiança de $95 \%$ foram extraídos dos estudos, e a significância estatística definida como $p<0,05$. Foram identificados 255 artigos, e por fim, analisados 15 estudos. A análise apresentou o escore prognóstico de Glasgow como fator de risco relacionado à sobrevida e considerado marcador prognóstico independente quando relacionado à sobrevida global dos pacientes com câncer gástrico que realizaram cirurgia e quimioterapia.
\end{abstract}

Palavras-chave: Neoplasias gástricas, Escala de resultado de Glasgow, Revisão sistemática, Metanálise, Sobrevida, Complicações pós-operatórias.

\begin{abstract}
The systemic inflammatory response and nutritional deficit are frequent features in cancer patients, and the Glasgow prognostic score has shown to be an excellent prognostic value in gastroesophageal cancer and a validated tool in the clinical evaluation of cancer patients. Thus, the present study aimed to analyze the association of Glasgow's prognostic score with the survival of patients with gastric carcinoma through systematic review and meta-analysis. The Preferred Reporting Items for Systematic Reviews and Meta-Analyses-PRISMA methodology was considered, with research on the Medline, Web of Science, and SCOPUS platforms, using appropriate descriptors. Clinical and observational studies published before September 30, 2017, and without language restriction were included. Inclusion criteria were the use of Glasgow prognostic score as a prognostic factor in patients with histological diagnosis of gastric carcinoma; over the age of 18; undergoing chemotherapy, radiation or surgery; with dosages of Reactive Protein $\mathrm{C}$ and albumin in the pre-treatment; and with data regarding survival during the study. The quality of the studies was assessed using the Newcastle-Ottawa Scale and the risk of bias using the Cochrane Collaboration tool. Hazard-Ratio and $95 \%$ Confidence Interval were extracted from the studies, with statistical significance defined as $p$ $<0.05$. Two hundred fifty-five articles were identified, and finally, 15 studies were analyzed. The analysis presented Glasgow prognostic score as a risk factor related with survival and considered an independent prognostic marker when related to the overall survival of patients with gastric cancer who underwent surgery and chemotherapy.
\end{abstract}

Keywords: Stomach neoplasms, Glasgow outcome scale, Systematic review, Meta-analysis, Survival, Postoperative complications.

1. Universidade Federal do Amazonas. Programa de Pós-Graduação em Cirurgia - PPGRACI. Manaus, (AM), Brasil

2. Universidade Federal do Amazonas. Faculdade de Medicina. Manaus, (AM), Brasil 


\section{INTRODUÇÃO}

Com o envelhecimento da população e o avanço nos cuidados médicos, o câncer tornou-se a principal causa de morte em países economicamente desenvolvidos e a segunda principal causa de morte em países em desenvolvimento ${ }^{1}$.

Dentre os cânceres, o câncer gástrico é uma das principais neoplasias malignas do mundo e ocupa a quinta posição em relação à incidência e a terceira em relação ao índice de mortalidade². No Brasil, é o quarto em incidência nos homens e o sexto nas mulheres ${ }^{3}$.

Nos pacientes com câncer, por sua vez, a resposta inflamatória sistêmica e o déficit nutricional são características frequentes ${ }^{4}$. A inflamação está associada a diferentes estádios do desenvolvimento do tumor, incluindo iniciação, promoção, conversão maligna, invasão e metástase e a proteína $C$ reativa (PCR), entre outros marcadores inflamatórios sistêmicos, tem apresentado possível aplicação na predição de um prognóstico ruim em portadores de câncer ${ }^{5}$.

A desnutrição, por sua vez, está associada a efeitos adversos físicos, psicológicos e clinicamente relevantes, contribuindo para pouca tolerância à terapia anticancerígena, reações adversas e piora da qualidade de vida ${ }^{6}$. O diagnóstico e o suporte nutricional adequados representam ganho considerável na sobrevivência global de pacientes com tumores malignos ${ }^{7,8}$.

A identificação de um escore nutricional e imunológico eficaz é primordial, pois condições préoperatórias relacionadas com resposta inflamatória sistêmica e com estado nutricional estão associadas com o prognóstico pós-operatório e os resultados a longo prazo de tumores malignos ${ }^{9,10}$.

Para avaliação da resposta inflamatória sistêmica foram criados escores utilizados como indicadores pré-intervenção e úteis no prognóstico de pacientes com câncer ${ }^{11}$, entre os quais, o escore prognóstico de Glasgow (GPS) ${ }^{12}$, que por avaliar a proporção da PCR e da albumina, um dos marcadores mais utilizados para avaliação nutricional ${ }^{13,14}$, mostrou excelente valor prognóstico no câncer gastresofágico inoperável ${ }^{15-18}$ e tem sido considerado a ferramenta mais amplamente validada na avaliação clínica de rotina para pacientes com câncer ${ }^{19-21}$. Em pacientes com câncer, os níveis de PCR podem aumentar devido à produção de citocinas relacionadas à inflamação, como fator de crescimento endotelial vascular e interleucina (IL). Por outro lado, a hipoalbuminemia é frequentemente observada em pacientes com câncer avançado e, geralmente, é considerado um marcador de desnutrição e caquexia. A baixa concentração de albumina está relacionada ao aumento da expressão de citocinas pró-inflamatórias, como IL-1, IL- 6 e fator de necrose tumoral, que modulam a produção de albumina. Assim, o GPS, baseado em uma combinação de níveis de PCR e albumina, pode refletir a presença de uma resposta inflamatória sistêmica e declínio nutricional progressivo em pacientes com câncer ${ }^{22-24}$. A partir desta revisão sistemática, espera-se caracterizar os achados resultantes da utilização deste escore prognóstico, podendo assim considerá-lo como método auxiliar na avaliação dos pacientes oncológicos com câncer gástrico, permitindo sua aplicabilidade na rede pública e rede privada, notadamente nos dois maiores centros de oncologia do Estado do Amazonas, Fundação Centro de Oncologia do Estado do Amazonas (FCECON) e Hospital Universitário Getúlio Vargas (HUGV).

\section{MÉTODO}

O estudo foi conduzido de acordo com a metodologia Preferred Reporting Items for Systematic Reviews and Meta-Analyses (PRISMA) ${ }^{25}$ e Cochrane Handbook ${ }^{26}$. Todos os passos foram executados por revisores independentes e quando necessário, um terceiro revisor.

\section{Fonte de informação e estratégia de busca}

A pesquisa foi realizada entre 28 e 30 de setembro de 2017, considerando estudos publicados anteriormente a setembro de 2017, sem restrição de linguagem. Foram utilizadas as bases de dados médicas e científicas PUBMED/Medline, Web of Science e SCOPUS com as palavras chaves: (Stomach Neoplasms) OU (Stomach Neoplasm) OU (Gastric Neoplasms) OU (Gastric Neoplasm) OU (Cancer of Stomach) OU (Stomach Cancers) OU (Gastric Cancer) OU (Gastric Cancers) OU (Gastric Cancers) OU (Stomach Cancer) OU (Stomach Cancers) OU (Cancer of the Stomach) OU (Familial Diffuse Gastric Cancer) E (Glasgow prognostic score) OU (GPS) de acordo com os descritores contidos no MESH. Uma busca secundária foi realizada nas referências identificadas nos artigos encontrados e que foram considerados como potenciais estudos a serem incluídos na seleção. 


\section{Critérios de elegibilidade}

Foram selecionados estudos observacionais e clínicos enquadrados nos seguintes critérios de inclusão: (I) a utilização do GPS como fator prognóstico em pacientes portadores de diagnóstico histológico de carcinoma gástrico, considerando a pontuação do GPS $(0,1,2)$ de acordo com a publicação de Forrest et al. (2003) ${ }^{18}$ em Glasgow, como segue: pacientes com PCR elevada ( $>10 \mathrm{mg} /$ dl) e hipoalbuminemia $(<3,5 \mathrm{~g} / \mathrm{dl})$ foi atribuída a pontuação 2 , pacientes com um destes parâmetros inadequados, receberam pontuação 1 , e para aqueles sem nenhuma destas anormalidades, foi atribuída pontuação 0; (II) pacientes com idade superior a 18 anos; (III) submetidos ao tratamento para a doença por quimioterapia, radioterapia ou cirurgia; (IV) com dosagem de PCR e albumina no pré-tratamento; (V) que apresentavam dados referentes à sobrevida dos pacientes durante $o$ estudo.

\section{Seleção dos estudos}

Os estudos foram selecionados e artigos em duplicidade e inelegíveis foram removidos. Os resumos dos artigos selecionados foram avaliados por dois pesquisadores, de forma independente. Casos discordantes eram definidos por um terceiro pesquisador. Foram avaliados os resumos que demonstraram GPS como fator prognóstico de uma população com diagnóstico carcinoma gástrico e se aplicável, eram incluídos na revisão sistemática e meta-análise.

\section{Extração de dados}

Os dados foram extraídos seguindo protocolo padronizado que consistiu nas tabelas de características e principais resultados dos estudos. Os dados obtidos foram: 1 - primeiro autor, ano de publicação, país da população estudada, tamanho amostral, dados demográficos idade e gênero do paciente, e período de acompanhamento; 2 - dados do tumor, incluindo tamanho, estágio, grau diferenciação e metastático; 3 - dados de sobrevivência, incluindo sobrevida global (OS), sobrevida livre de doença (PFS); e 4 - valores do GPS 0,1 e 2 .

Foram constituídos dois subgrupos: Grupo Cirúrgico (GC), quando os pacientes no estudo individual receberam terapia cirúrgica, seguido de apenas alguns deles recebendo terapia extra cirúrgica adicional, isto é, quimioterapia ou radioterapia; e Grupo Não Cirúrgico (GNC), quando todos os pacientes no estudo individual foram tratados por intervenção não-cirúrgica e/ou alguns pacientes que foram submetidos à operação no seguimento.

A OS foi definida como o intervalo entre o tratamento médico e a morte do paciente ou o último acompanhamento. A PFS foi calculada a partir da data do tratamento até a detecção da recidiva tumoral ou a morte por qualquer causa. O grau de diferenciação do tumor também foi estratificado em bem diferenciado, moderadamente diferenciado, pouco diferenciado e indiferenciado. $O$ estadiamento do tumor foi observado usando a Classificação de Estadiamento TNM da sétima edição do American Joint Committee on Cancer como I/II e III/IV27. Também foram coletados os dados de Razão de Risco (HR) e intervalo de confiança de $95 \%$. A relevância estatística foi definida como o $p<0,05$.

\section{Avaliação da qualidade dos estudos}

A avaliação da qualidade foi realizada de forma independente, em cada um dos estudos incluídos, por dois revisores, usando a Escala de Avaliação da Qualidade de Newcastle-Ottawa $(\text { NOS })^{28}$. Os artigos com pontuação $\geq 7$ foram considerados estudos de alta qualidade. Qualquer desacordo foi abordado por um terceiro revisor. $O$ risco de viés de qualidade dos estudos foi avaliado através da ferramenta da Cochrane Collaboration ${ }^{26}$.

\section{Análise dos dados}

A análise estatística dos dados foi realizada com o uso da plataforma Stata (versão 14.0). Utilizaram-se os pacotes 'metaprop' e 'metareg'29. $O$ teste Qui-quadrado baseado no teste $\mathrm{Q}\left(\mathrm{I}^{2}\right)$ foi usado para quantificar a presença de heterogeneidade com a representação do Forest plot para heterogeneidade ${ }^{30}$. Quando os valores de $I^{2}$ não foram estatisticamente significativos $\left(\mathrm{I}^{2}<50 \%, \mathrm{p}>0,05\right)$ o modelo de efeito fixo foi utilizado para estimar o valor de HazardRatio (HR) agrupado. Por outro lado, quando a heterogeneidade foi significante $\left(\mathrm{I}^{2}>50 \%, \mathrm{p}<0,05\right)$ o modelo de efeitos aleatórios foi usado para cálculo de $H R^{31}$. Em ambos os métodos, o valor de $p<0,05$ foi considerado estatisticamente significante. Os testes 
de Begg e a regressão linear de Egger $(p<0,05)$ foram empregados para avaliar potenciais vieses de publicação das associações trazidas e a assimetria no gráfico de Forest plot também foi considerada. Avaliou-se, ainda, a existência do efeito de estudos pequenos (small-study effect) mediante a inspeção visual do gráfico de funil e o teste de Egger ${ }^{32}$.

\section{RESULTADOS}

O fluxograma da pesquisa está demonstrado na Figura 1. 0 algoritmo de busca inicial recuperou um total de 255 estudos. Após a revisão, 25 estudos identificados sobre o GPS e o prognóstico do câncer gástrico foram avaliados. Destes, dez estudos foram excluídos devido aos seguintes motivos: dois não forneceram dados suficientes sobre o seguimento dos pacientes, três não estratificaram o câncer gástrico dos outros tumores do estudo, um estudo utilizou somente - GPS modificado na avaliação prognóstica e quatro não forneceram dados sobre a sobrevida dos pacientes ou não preencheram os critérios de inclusão. Portanto, 15 estudos publicados entre 2011 e 2017 foram inclusos nesta revisão sistemática e meta-análise.
Os estudos selecionados apresentaram delineamento de coorte e, em sua maior parte, foram realizados na Ásia, sendo seis estudos realizados na China, cinco no Japão e dois na Coreia do Sul. $\mathrm{Na}$ Europa, um na Alemanha e um na República Tcheca. O GPS foi calculado com base em dados de laboratório de pré-tratamento usando as dosagens de PCR $(10 \mathrm{mg} / \mathrm{dl})$ e albumina $(3,5 \mathrm{~g} / \mathrm{dl})$, sem diferenças nos valores de referência. Três destes estudos envolveram menos de 100 pacientes e 12 coortes tinham mais de 100 pacientes. O sexo preponderante em todos os estudos foi o masculino. O seguimento dos pacientes ocorreu entre 9,1 meses e 7 anos. A faixa etária mais prevalente foi a quinta década de vida. O principal tratamento empregado, relacionado com o uso do GPS, foi a cirurgia em nove estudos e a quimioterapia em seis, este tratamento, especialmente, em pacientes pós-ressecção curativa, como terapia adjuvante e nos pacientes metastáticos em caráter paliativo (Tabela 1).

A pontuação preponderante do GPS nos estudos foi o GPS 0. A razão de riscos (HR) e intervalo de confiança (IC) $95 \%$ relacionados com dados de sobrevida, foram extraídos diretamente da literatura original em 14 das coortes avaliadas. O HR

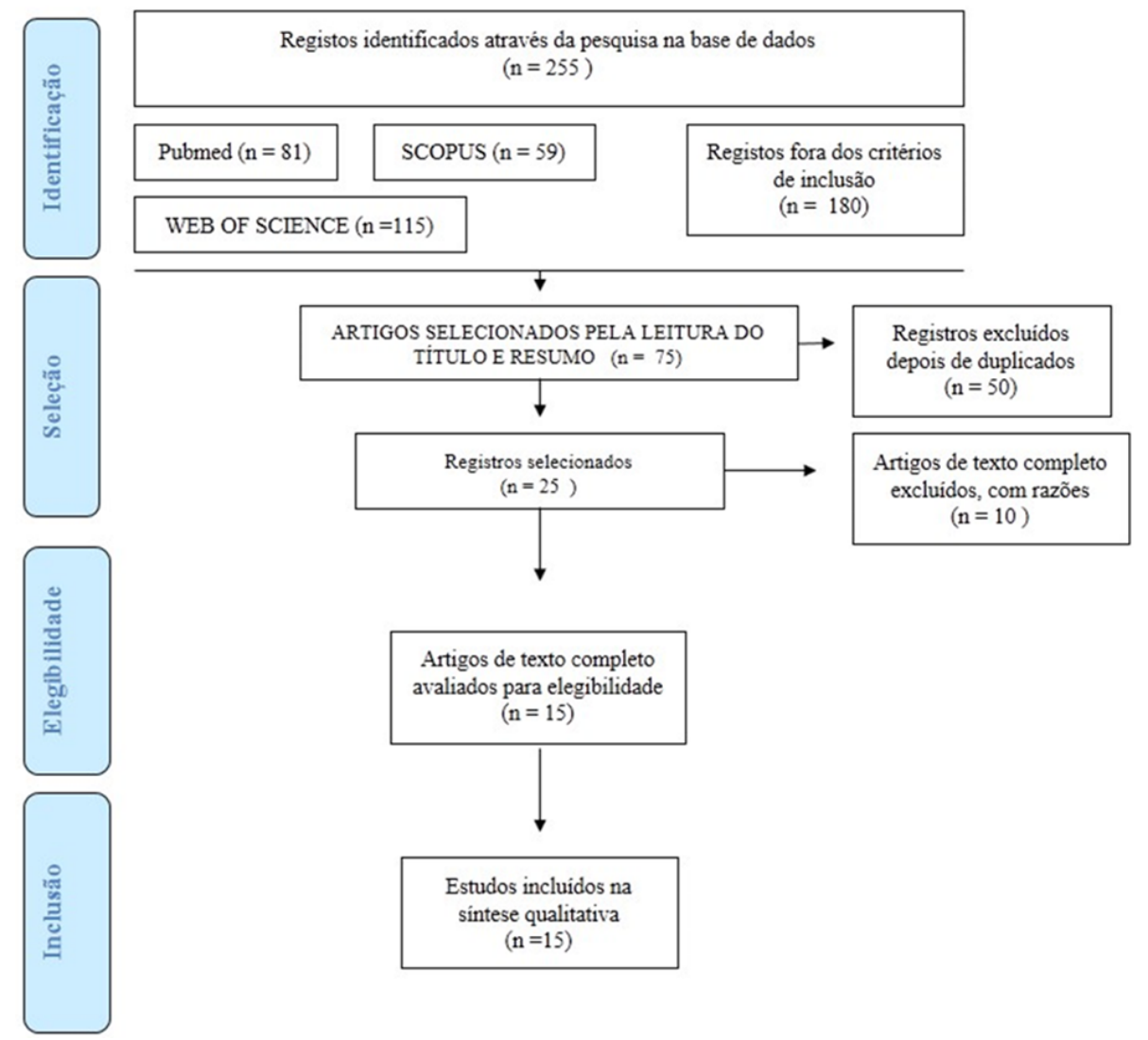

Figura 1. Fluxograma de identificação, seleção, elegibilidade e inclusão dos artigos para revisão sistemática e meta-análise segundo o protocolo PRISMA (Prefered Reporting Items for Systematic Reviews and Meta-analyses). 
Tabela 1. Características dos estudos incluídos na revisão sistemática sobre a associação dos valores do escore de Glasgow (GPS) com sobrevida de pacientes com câncer gástrico, publicados no período de 2011 a 2017.

\begin{tabular}{|c|c|c|c|c|c|c|}
\hline $\begin{array}{l}\text { Estudo } \\
\text { Primeiro } \\
\text { autor, ano }\end{array}$ & País & $\begin{array}{c}\text { Período de } \\
\text { acompanhamento }\end{array}$ & $\begin{array}{c}\text { Total de } \\
\text { pacientes }\end{array}$ & $\begin{array}{l}\text { Idade em } \\
\text { anos }\end{array}$ & $\begin{array}{c}\text { Tratamento } \\
\text { predominante }\end{array}$ & Estadiamento \\
\hline $\begin{array}{l}\text { Hwang, } 2011 \\
\text { (33) }\end{array}$ & Coreia do Sul & 11,4 meses & 402 & $\begin{array}{c}\geq 60(199)< \\
60(203)\end{array}$ & Quimioterapia & IV \\
\hline $\begin{array}{l}\text { Hwang, } 2012 \\
\text { (34) }\end{array}$ & Coreia do Sul & 9,1 meses & 125 & $66(25$ a 81$)$ & Quimioterapia & IV \\
\hline $\begin{array}{l}\text { Ishizuka, } 2014 \\
\text { (35) }\end{array}$ & Japão & $52-38,7$ meses & 650 & $\begin{array}{l}\leq 70(190) \\
>70(108)\end{array}$ & Cirurgia & I/II/III/IV \\
\hline $\begin{array}{l}\text { Kubota, } 2012 \\
(36)\end{array}$ & Japão & 35,9 meses & 1017 & $\begin{array}{c}62,9 \pm 11,7 \\
(26 \text { a } 91)\end{array}$ & Cirurgia & II/III \\
\hline $\begin{array}{l}\text { Kunisaki, } 2012 \\
\text { (37) }\end{array}$ & Japão & 14,5 meses & 83 & $67,7(37-91)$ & Quimioterapia & III/IV \\
\hline Li, 2014 (38) & China & 96 meses & 384 & $\begin{array}{l}>65(82) \\
\leq 65(252)\end{array}$ & Quimioterapia & IV \\
\hline Liu, 2015 (39) & China & 25 meses & 455 & $59(19$ a 86$)$ & Cirurgia & I/II/III \\
\hline Liu, 2017 (40) & China & 33 meses & 1056 & $58(19$ a 89$)$ & Cirurgia & I/II/III \\
\hline $\begin{array}{l}\text { Melling, } 2016 \\
(41)\end{array}$ & Alemanha & 25,1 meses & 88 & $\begin{array}{l}<60(34) \\
>60(54)\end{array}$ & Cirurgia & I/II/III/IV \\
\hline $\begin{array}{l}\text { Namikawa, } \\
2016 \text { (42) }\end{array}$ & Japão & 84 meses & 224 & 69 (19 a 89) & Quimioterapia & IV \\
\hline $\begin{array}{l}\text { Nozoe, } 2011 \\
(43)\end{array}$ & Japão & 1,6 a 111 meses & 232 & 67 (27 a 89) & Cirurgia & I/II/III/IV \\
\hline Pan, 2015 (44) & China & 37 meses & 207 & $\begin{array}{l}<64(106) \\
\geq 64(101)\end{array}$ & Cirurgia & I/II/III/IV \\
\hline $\begin{array}{l}\text { Sachlova, } 2014 \\
\text { (45) }\end{array}$ & $\begin{array}{l}\text { República } \\
\text { Tcheca }\end{array}$ & 36 meses & 91 & $\begin{array}{l}<65(56) \\
\geq 65(35)\end{array}$ & Quimioterapia & III/IV \\
\hline Sun, 2016 (46) & China & 36 meses & 873 & 59 (19 a 89) & Cirurgia & I/II/III \\
\hline $\begin{array}{l}\text { Wang, } 2012 \\
\text { (47) }\end{array}$ & China & 39,9 meses & 324 & $\begin{array}{c}\geq 65(94)< \\
65(230)\end{array}$ & Cirurgia & III \\
\hline
\end{tabular}

(análise multivariada) relacionado à sobrevida global, estava presente em 13 dos 15 estudos, permitindo a realização da meta-análise (Tabela 2 ).

\section{Avaliação da qualidade e risco de viés dos estudos}

Os resultados da qualidade dos estudos com base nos critérios da escala de qualidade de Newcastle-Ottawa (NOS) ${ }^{28}$ demonstraram que a maioria obteve a pontuação mínima exigida (7 pontos) para serem incluídos, enquanto dois obtiveram seis pontos. Nove dos estudos obtiveram pontuação máxima ( 9 pontos) nesta escala binária. A pontuação maior ou igual a sete indica que os artigos possuem relevância científica para produção da revisão sistemática e meta-análise.
A avaliação do risco de viés dos estudos demonstrou que nenhum dos estudos teve avaliação cega, tanto para os pacientes quanto para os pesquisadores, aspecto metodológico que pode representar viés de coleta dos dados. Outras fontes de vieses seriam os estudos com a seleção de pacientes com estadiamento localmente avançado e metastático, que devido ao estado mórbido e a desnutrição produzidos pelas neoplasias, podem levar a um direcionamento para o GPS com maior pontuação (1 ou 2), podendo interferir estatisticamente nas análises dos estudos.

\section{Meta-análise dos dados obtidos}

A meta-análise demonstrou a associação entre a maior pontuação GPS e pior sobrevida global (OS), 
Tabela 2. Resultados dos estudos incluídos na revisão sistemática abordando a associação dos valores de escore de Glasgow (GPS) com a sobrevida em pacientes com câncer gástrico, publicados no período de 2011 a 2017.

\begin{tabular}{|c|c|c|c|c|c|}
\hline \multirow{2}{*}{$\begin{array}{l}\text { Estudo } \\
\text { Primeiro autor, } \\
\text { ano }\end{array}$} & \multirow{2}{*}{$\begin{array}{l}\text { GPS } \\
(0 / 1 / 2)\end{array}$} & \multirow{2}{*}{$\begin{array}{l}\text { Diferenciação } \\
\text { tumoral } \\
\text { Bem ou } \\
\text { moderado/ } \\
\text { pouco } \\
\text { diferenciado }\end{array}$} & \multicolumn{3}{|c|}{ Sobrevida associada ao GPS } \\
\hline & & & $\begin{array}{l}\text { Dados de } \\
\text { sobrevida }\end{array}$ & HR (Intervalo Confiança de 95\%) & $p$ valor \\
\hline Hwang, 2011 (33) & $238 / 111 / 53$ & ND & $\begin{array}{l}\text { PFS (U) } \\
\text { OS (M) }\end{array}$ & $\begin{array}{l}\text { ND } \\
\text { GPS } 1 \text { vs. GPS } 0=1,75(1,37-2,26) \\
\text { GPS } 2 \text { vs. GPS } 0=1,79(1,29-2,47)\end{array}$ & $\begin{array}{l}0,001 \\
0,001 \\
0,001\end{array}$ \\
\hline Hwang, 2012 (34) & $50 / 44 / 31$ & ND & $\begin{array}{l}\text { OS (M) } \\
\text { PFS (U) }\end{array}$ & $\begin{array}{c}\text { GPS } 1 / 2 \text { vs. GPS } 0=1,88(1,24-2,85) \\
\text { ND }\end{array}$ & $\begin{array}{l}0,003 \\
0,006\end{array}$ \\
\hline Ishizuka, 2014 (35) & $298 / 99 / 28$ & ND & $\begin{array}{l}\text { OS (U) } \\
\text { OS (M) }\end{array}$ & $\begin{array}{c}4,138(2,42-7,058) \\
\text { GPS1/2 vs. GPS } 0=2,048(1,002- \\
4,185)\end{array}$ & $\begin{array}{c}<0,001 \\
0,049\end{array}$ \\
\hline Kubota, 2012 (36) & $956 / 40 / 21$ & $447 / 550$ & $\begin{array}{l}\text { OS }(M) \\
\operatorname{CSS}(M)\end{array}$ & $\begin{array}{l}\text { GPS } 1 \text { vs. GPS } 0=1,82(1,00-3,11) \\
\text { GPS } 2 \text { vs. GPS } 0=5,23(2,30-10,37) \\
\text { GPS } 1 \text { vs. GPS } 0=1,26(0,54-2,56) \\
\text { GPS } 2 \text { vs. GPS } 0=5,07(1,94-11,41)\end{array}$ & $\begin{array}{c}0,0499 \\
<0,0003 \\
0,5702 \\
0,0018\end{array}$ \\
\hline Kunisaki, 2012 (37) & $35 / 24 / 24$ & $14 / 21$ & DSS (M) & $\begin{array}{c}\text { GPS } 1 \text { vs. GPS } 0=1,365(0,689- \\
2,704) \\
\text { GPS } 2 \text { vs. GPSO } 0=3,446(1,772- \\
6,701)\end{array}$ & $\begin{array}{l}0,001 \\
0,001\end{array}$ \\
\hline $\mathrm{Li}, 2014(38)$ & $123 / 62 / 5$ & $79 / 255$ & $\begin{array}{l}\text { OS (U) } \\
\text { PFS (U) } \\
\text { OS (M) }\end{array}$ & $\begin{array}{c}\mathrm{ND} \\
\mathrm{ND} \\
\text { GPS1/2 vs GPS } 0=1,62(1,124- \\
2,339)\end{array}$ & $\begin{array}{l}0,006 \\
0,002 \\
0,010\end{array}$ \\
\hline Liu, 2015 (39) & $350 / 92 / 13$ & ND & $\begin{array}{l}\text { OS (U) } \\
\text { OS (M) }\end{array}$ & $\begin{array}{c}\mathrm{ND} \\
\text { GPS1/2 vs. GPS } 0=1,160(0,910- \\
1,478)\end{array}$ & $\begin{array}{c}<0,001 \\
0,230\end{array}$ \\
\hline Liu, 2017 (40) & $852 / 154 / 50$ & $202 / 854$ & $\begin{array}{l}\text { OS }(U) \\
\text { OS }(M)\end{array}$ & $\begin{array}{c}\text { ND } \\
\text { GPS } 1 \text { vs. GPS } 0=1,433(0,976- \\
2,104) \\
\text { GPS } 2 \text { vs. GPS } 0=1,889(1,107- \\
3,224)\end{array}$ & $\begin{array}{c}<0,001 \\
0,067 \\
0,020\end{array}$ \\
\hline Melling, 2016 (41) & $41 / 21 / 26$ & $24 / 58$ & OS $(U)$ & $\begin{array}{l}\text { ND } \\
\text { GPS } 0 \text { vs. } 1 \\
\text { GPS } 0 \text { vs. } 2 \\
\text { GPS } 1 \text { vs. } 2\end{array}$ & $\begin{array}{c}0,036 \\
<0,001 \\
0,069\end{array}$ \\
\hline $\begin{array}{l}\text { Namikawa, } 2016 \\
(42)\end{array}$ & ND & ND & $\begin{array}{l}\text { OS (M) } \\
\text { OS (U) }\end{array}$ & $\begin{array}{c}\text { GPS } 1 / 2 \text { vs. GPS } 0=1,297(0,667- \\
2,552) \\
\text { ND }\end{array}$ & $\begin{array}{l}0,444 \\
0,004\end{array}$ \\
\hline Nozoe, 2011 (43) & $140 / 64 / 28$ & $114 / 118$ & OS (M) & GPS 0,1 vs. $2=3,425(1,211-9,709)$ & 0,020 \\
\hline Pan, 2015 (44) & $103 / 71 / 33$ & $154 / 33$ & $\begin{array}{l}\text { OS }(U) \\
\text { DFS (U) } \\
\text { OS (M) } \\
\text { DFS (M) }\end{array}$ & $\begin{array}{c}\text { ND } \\
\text { ND } \\
\text { GPS } 1 / 2 \text { vs. GPS } 0=0,024(1,043- \\
1,698) \\
\text { GPS } 1 / 2 \text { vs. GPS } 0=0,038(1,015- \\
1650)\end{array}$ & $\begin{array}{c}<0,001 \\
<0,001 \\
0,024 \\
0,038\end{array}$ \\
\hline Sachlova, 2014 (45) & $37 / 31 / 23$ & $182 / 64$ & OS (M) & $\begin{array}{l}\text { GPS } 1 \text { vs. GPS }=0,93(0,85-4,40) \\
\text { GPS } 2 \text { vs. GPS } 0=6,63(2,42-18,17)\end{array}$ & $\begin{array}{l}0,120 \\
<0,001\end{array}$ \\
\hline Sun, 2016 (46) & $464 / 98 / 39$ & $197 / 676$ & $\begin{array}{l}\text { OS }(U) \\
\text { OS }(M))\end{array}$ & $\begin{array}{c}\text { ND } \\
\text { GPS1/2 vs. GPS } 0=1,60(1,37-1,89)\end{array}$ & $\begin{array}{l}<0,001 \\
<0,001\end{array}$ \\
\hline Wang, 2012 (47) & $248 / 58 / 18$ & $51 / 273$ & $\begin{array}{l}\text { DFS (M) } \\
\text { OS (M) }\end{array}$ & $\begin{array}{c}\text { GPS } 1 / 2 \text { vs. GPS } 0=1,429(1,128- \\
1,810) \\
\text { GPS } 1 / 2 \text { vs. GPS } 0=1,397(1,070- \\
1,824)\end{array}$ & $\begin{array}{c}<0,003 \\
0,014\end{array}$ \\
\hline
\end{tabular}

GPS: escore prognóstico de Glasgow; HR: Razão de Risco; OS: sobrevida global; PFS: sobrevida livre de progressão; DSS: sobrevida doença específica; CSS: sobrevida câncer específica; DFS: sobrevida livre de doença; (U): análise univariada; (M): análise multivariada; ND: não descrito. 
indicando que o escore elevado é fator de risco para piora na sobrevida. Com índices de heterogeneidade aceitáveis, conforme demonstrado no grupo (1-0) com I-squared de $0 \%$ e $p=0,794$, no grupo (2-0) com I-squared de $27,4 \%$ e $p=0,247$ e no grupo (1/2-0) com I-squared de $4,1 \%$ e $p=0,400$. Dois estudos não foram incluídos devido à falta de dados de sobrevida global e pontuação NOS $\leq 7(37,41)$ (Figura 2$)$.
Estratificados os pacientes com tratamento cirúrgico, verificou-se aumento do risco do GPS elevado, pré-tratamento associado à sobrevida global, com todos os estudos apresentando aumento do risco. Porém, no grupo de comparação (2-0) observou-se o aumento da heterogeneidade com I-squared de $59,4 \%$ e $p=0,116$ (Figura 3 ).

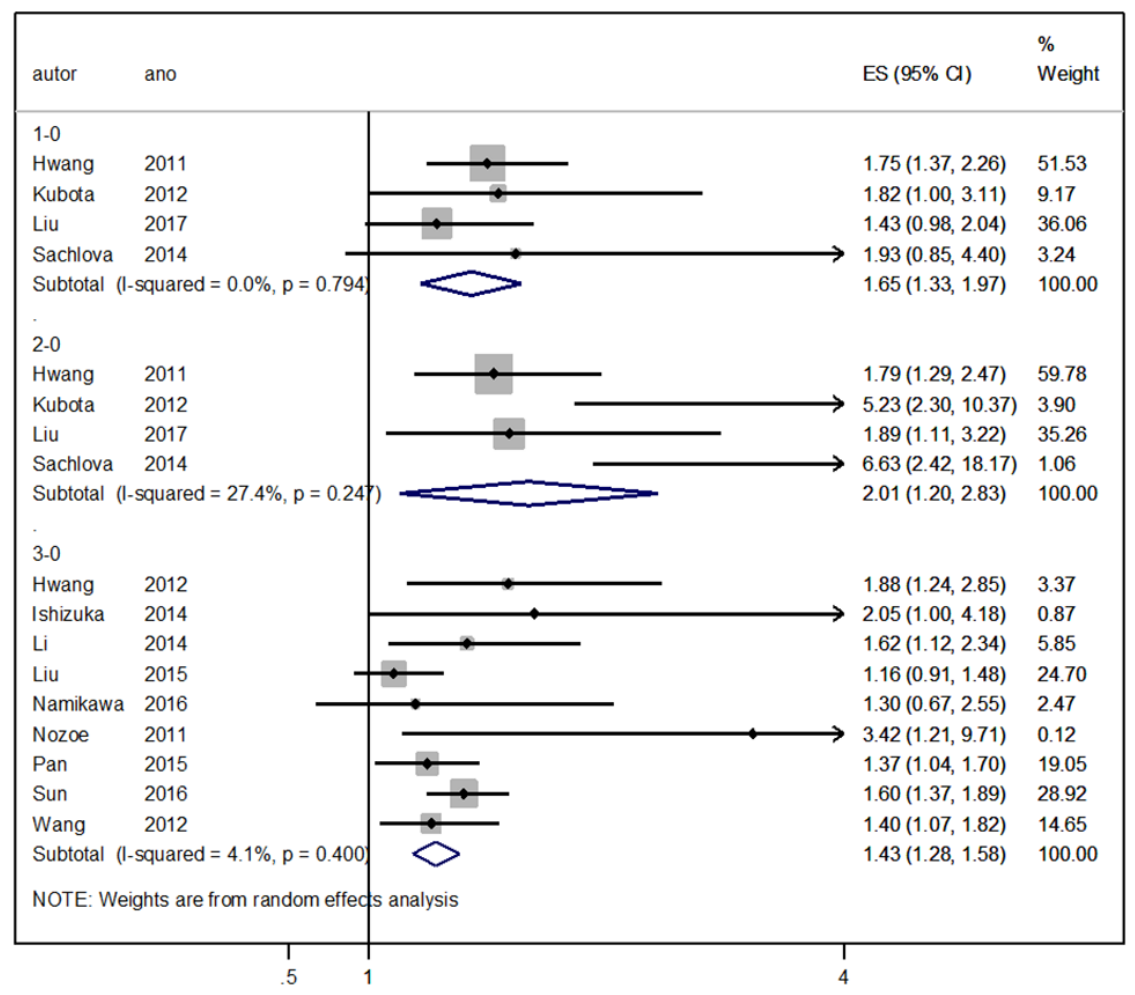

Figura 2. Gráfico "forest plot" entre o escore prognóstico de Glasgow (GPS) pré-tratamento e sobrevida global (OS) em pacientes com câncer gástrico submetidos tanto a tratamento cirúrgico quanto à quimioterapia.

Grupo 1-0: Comparação entre GPS 0-1; Grupo 2-0: Comparação entre GPS 0-2; Grupo 3-0: Comparação entre GPS 1/2- 0. GPS: escore prognóstico de Glasgow; OS: sobrevida global; ES=HR: razão de risco; Cl: intervalo de confiança.

Em pacientes que receberam tratamento quimioterápico para câncer gástrico, observouse a redução da sobrevida global quanto maior a pontuação do GPS, porém, com aumento da heterogeneidade no grupo (2-0) com I-squared de $83 \%$ e $p=0,015$ (Figura 4 ).

\section{DISCUSSÃO}

A resposta inflamatória e o declínio nutricional são dois achados evidentes nos pacientes com câncer ${ }^{11}$. Viu-se a necessidade de índices que avaliem a resposta inflamatória e nutricional nos pacientes oncológicos, a fim de evitar tratamentos desnecessários e dispendiosos financeiramente para o sistema público e sem benefício na sobrevida ou qualidade de vida dos pacientes com neoplasia. Lembrando que índices complexos com múltiplas variáveis são menos utilizados ou ineficazes na avaliação. Uma alternativa preferida é utilizar um único índice de prognóstico ou talvez uma ferramenta que associe alguns índices. Outra opção é o GPS, por utilizar dois marcadores (PCR e albumina) de fácil obtenção e baixo custo através de dosagem sérica no pré-tratamento ${ }^{19}$.

Os pacientes com neoplasia maligna necessitam de uma avaliação cada vez mais abrangente e multidisciplinar, para que seja proposto 


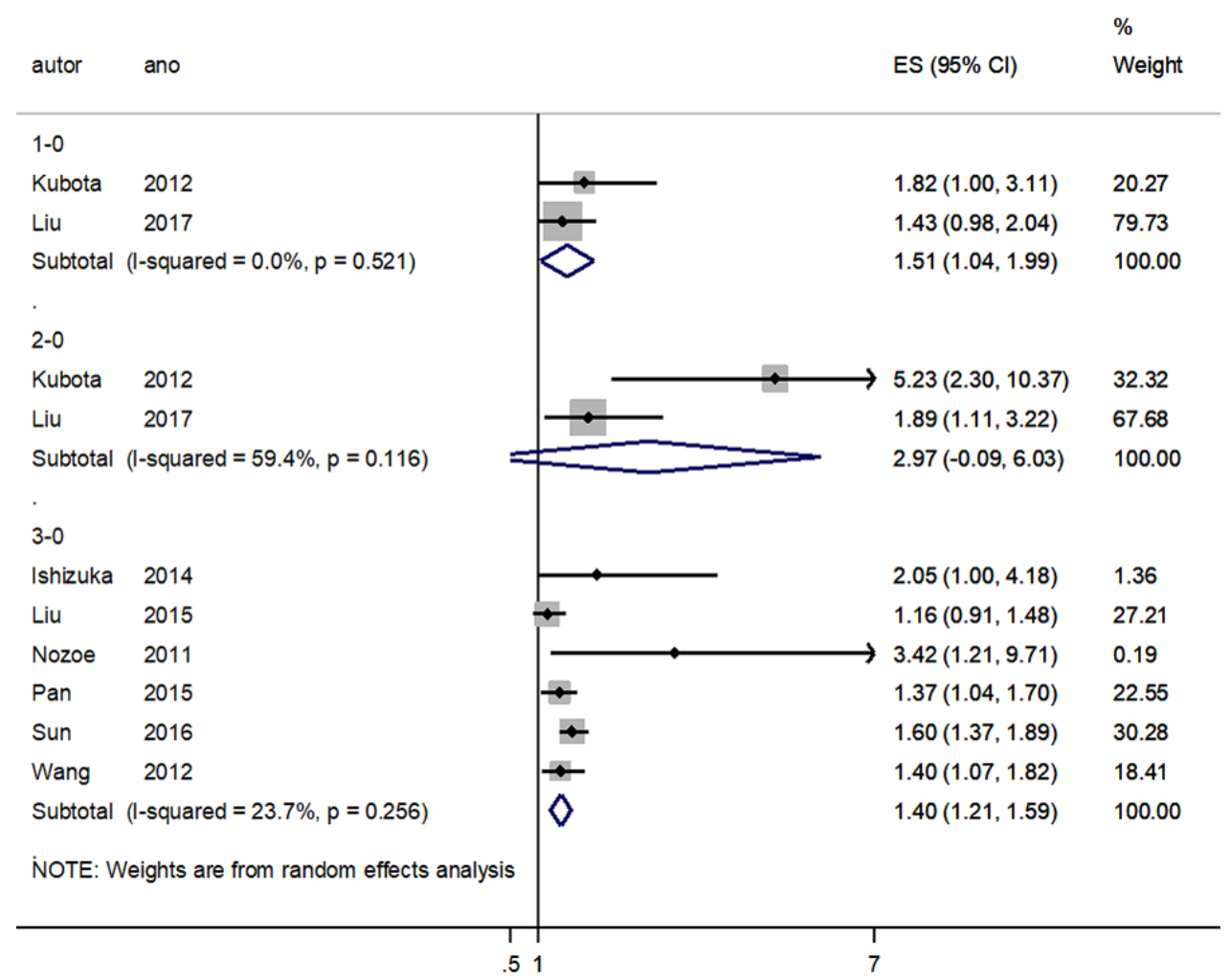

Figura 3. Gráfico "forest plot" entre o escore prognóstico de Glasgow (GPS) pré-tratamento e sobrevida global (OS) em pacientes com câncer gástrico submetidos a tratamento cirúrgico.

Grupo 1-0: Comparação entre GPS 0-1; Grupo 2-0: Comparação entre GPS 0-2; Grupo 3-0: Comparação entre GPS 1/2- 0 . GPS: escore prognóstico de Glasgow; OS: sobrevida global; ES=HR: razão de risco; Cl: intervalo de confiança.

um tratamento curativo ou paliativo adequado e se tenha uma visão universal do estado do paciente. Índices de avaliação clínica do estado geral do paciente atualmente utilizados, como o Karnofsky Performance Status (KPS) ${ }^{49}$, não são suficientes para definir o tipo de tratamento a ser instituído, necessitando de métodos auxiliares como avaliação nutricional e avaliação do estado inflamatório.

\section{Sobrevida}

Nos mais diversos cânceres e topografias, o GPS demonstrou sua relação com a sobrevida, como, por exemplo, nos tumores ginecológicos: câncer de colo uterino ${ }^{50}$ e câncer de mama51; nos tumores do trato gastrointestinal: carcinoma hepatocelular ${ }^{48,52}$, câncer de pâncreas ${ }^{12,53,54}$ e carcinoma colorretal ${ }^{11,55-57}$; e, em tumores do trato geniturinário como o carcinoma renal ${ }^{58,59}$. Tem sido demonstrada, assim, sua utilização em populações acometidas por neoplasia e capacidade definidora de pior prognóstico, quanto maior o escore. Entretanto, no câncer gástrico ainda não vinha ficado evidenciado o GPS como um escore prognóstico com ampla utilização e validação ${ }^{60}$. Foram descritos inúmeros escores prognósticos e nutricionais (Relação Proteína C Reativa-PCR/Alb, Relação Neutrófilo-LinfócitoNLR, Razão Plaquetas/Linfócitos-PLR, e Prognostic Nutritional Index-PNI) na tentativa de demonstrar a associação com a sobrevida. Fato demonstrado com este estudo, com avaliação de sua utilização tanto nos pacientes cirúrgicos quanto nos que realizaram quimioterapia para avaliação da sobrevida global.

\section{Idade}

A associação da idade com o GPS com significância estatística $(p=0,003)$ foi observada na análise univariada conduzida no estudo de coorte de Ishizuka et al. ${ }^{35}$. Entretanto, as coortes acompanhadas por Nozoe et al. ${ }^{43}$, Hwang et al. ${ }^{33}$, Kunisaki et al. ${ }^{37}$, Wang et al. ${ }^{47}$, e Melling et al. ${ }^{41}$ não demonstraram significância estatística nessa associação, levando a concluir que a associação GPS e idade, nos estudos analisados, não pode ser confirmada. 


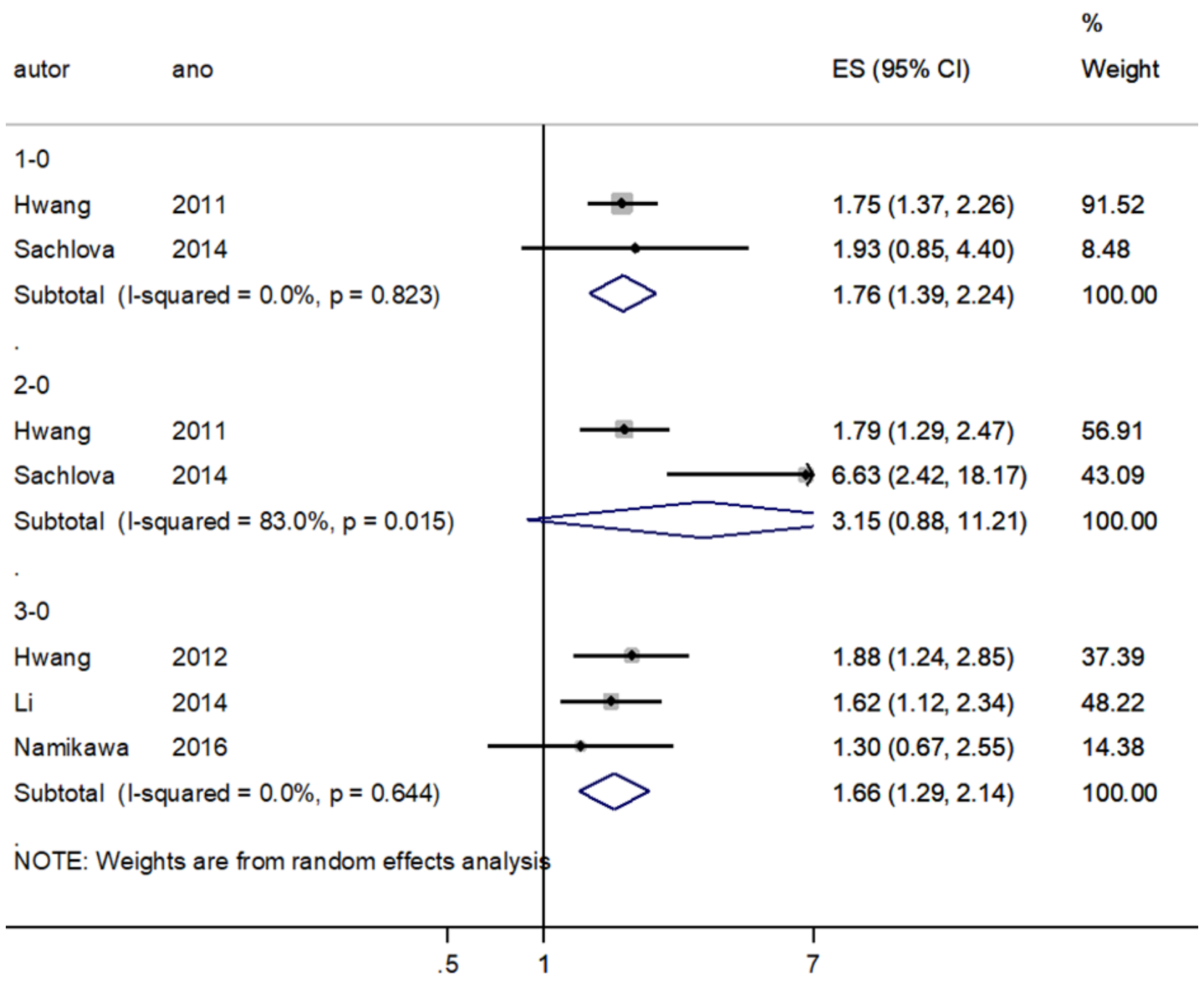

Figura 4. O gráfico "forest plot" entre o escore prognóstico de Glasgow (GPS) pré-tratamento e sobrevida global (OS) em pacientes com câncer gástrico submetidos a tratamento quimioterápico.

Grupo 1-0: Comparação entre GPS 0-1; Grupo 2-0: Comparação entre GPS 0-2; Grupo 3-0: Comparação entre GPS 1/2- 0. GPS: escore prognóstico de Glasgow; OS: sobrevida global; ES=HR: razão de risco; Cl: intervalo de confiança.

\section{Tratamento}

O GPS demonstrou potencial para ser utilizado na avaliação prognóstica em cirurgias com intenção curativa e, também, na avaliação de tratamento quimioterápico adjuvante após a cirurgia ${ }^{36,39}$. Observou-se também a sua utilização na avaliação prognóstica de drogas de primeira e segunda linha para quimioterapia em caráter paliativo $0^{33,34,37,38}$.

\section{Prognóstico versus Estadiamento}

A relação prognóstica com o estadiamento TNM foi observada nas coortes de Kunisaki et al. ${ }^{37}$, Melling et al. ${ }^{41} \mathrm{e}$ Wang et al. ${ }^{47}$, sem significância estatística ( $p=0,105, p=0,258$ e $p=0,088$, respectivamente). As coortes de Ishizuka et al..$^{35}$ e Nozoe et al. ${ }^{43}$ apresentaram relevância estatística nessa associação, $\operatorname{com} p<0,001$. Pan et al. ${ }^{44}$ demonstraram que o GPS e o TNM são preditores superiores de sobrevida, comparados com Relação Neutrófilo-Linfócito (NLR), Razão Plaquetas/ Linfócitos (PLR), Índice de Proliferação (PI) e Índice de Prognóstico Nutricional (PNI), em pacientes submetidos à ressecção cirúrgica. O TNM já é validado e amplamente utilizado como preditor do prognóstico dos pacientes com câncer assim como o GPS, porém, a associação não demonstrou o mesmo valor. 


\section{Complicações pós-operatórias}

O estudo de Kubota et al. ${ }^{36}$ representou a associação do GPS com as complicações pósoperatórias, porém, não apresentou significância estatística $(p=0,9289)$.

\section{Avaliação histopatológica}

Tendo como parâmetro a utilização da avaliação histopatológica quanto à invasão venosa e linfática, a coorte de Wang et al. ${ }^{47}$ apresentou os dois parâmetros agrupados na associação com 0 GPS, mas sem significância estatística $(p=0,536)$.

\section{Linfática}

Na avaliação da invasão linfática dois estudos de coorte apresentaram significância estatística na associação com o GPS, Ishizuka et al. ${ }^{35}$ e Nozoe et al. ${ }^{43}$ com o $p<0,001$ e 0,001, respectivamente, e a coorte acompanhada por Melling et al. ${ }^{41}$ não apresentou associação $(p=0,792)$.

\section{Invasão venosa}

Quanto à invasão venosa, três coortes apresentaram relação com o GPS, Ishizuka et al. ${ }^{35}$, Melling et al. ${ }^{41}$ e Nozoe et al. ${ }^{43}$, com $p<0,001$, 0,0001 e 0,008 , respectivamente. Demonstrando, desta forma, que os achados histológicos de pior prognóstico apresentam correlação com um maior escore de Glasgow.

\section{Grau de diferenciação}

O grau de diferenciação tumoral mais evidenciado nos estudos foi o pouco diferenciado ou o indiferenciado, com exceção do estudo de Sachlova, Majek e Tucek ${ }^{45}$, que apresentou o tipo bem diferenciado e moderadamente diferenciado. Outras cinco coortes não apresentaram esta informação, conforme relatado na Tabela 2 . A relação estatística do GPS com o grau de diferenciação foi descrita nas coortes acompanhadas por Melling et al. ${ }^{41}$, Ishizuka et al. ${ }^{35}$, Nozoe et al. ${ }^{43}$, e Wang et al. ${ }^{47}, \operatorname{com} p=0,243$, $p<0,001, p=0,294$ e $p=0,672$, respectivamente, demonstrando a não associação do alto GPS com o grau de diferenciação.

\section{Sobrevida global}

Os dados de sobrevida global (OS) nas nove coortes em que o tratamento preponderante foi a cirurgia $35,36,39-41,43,44,46,47$, apresentaram associação com um alto GPS na evolução para um pior prognóstico, na avaliação da razão de risco (HR) com análise univariada $[4,138$ IC $95 \%(2,42-7,058)-1,62$ IC 95\% $(1,124-2,339)]$ com significância estatística p (<0,001-0,014). Nas demais coortes $33,34,37,38,42,45$, o tratamento preponderante foi a quimioterapia e houve relação do alto GPS com um pior prognóstico durante o tratamento, com o HR na análise multivariada $[1,297$ IC $95 \%(0,667-2,552)-1,62$ $(1,124-2,339)]$ e $p(0,444-0,010)$.

Estes dados demonstram a validação da utilização do GPS como marcador de prognóstico nos pacientes com câncer gástrico e a redução da sobrevida global quanto maior sua pontuação (GPS 1 e 2). Observou-se na meta-análise que, independentemente do tratamento empregado, cirurgia ou quimioterapia, o GPS elevado representa um risco aumentado, seja em prognóstico e/ou complicações para os pacientes com câncer gástrico.

O presente estudo possui duas limitações em virtude de todos os estudos serem do tipo coorte, sem cegamento dos pesquisadores e pacientes. A origem dos artigos, em sua maioria, é da Ásia. Pontos positivos observados se traduzem pela avaliação da qualidade dos estudos pela NOS e pela análise do risco de viés, demonstrando serem artigos com potencial para utilização na revisão sistemática e meta-análise.

\section{CONCLUSÃO}

A análise demonstrou que o GPS é marcador prognóstico independente quando relacionado à sobrevida global dos pacientes com câncer gástrico que realizaram cirurgia e/ou quimioterapia, adjuvante ou paliativa, evidenciando-se piora na sobrevida global notadamente quanto maior o GPS, podendo ser utilizado na prática clínica como escore auxiliar para tratamento dos portadores desta doença. 


\section{REFERÊNCIAS}

1.Jemal A, Bray F, Center MM, Ferlay J, Ward E, Forman D. Global cancer statistics. CA Cancer J Clin. 2011;61(2):69-90. Doi: 10.3322/caac.20107.

2.Ferlay J, Soerjomataram I, Dikshit R, Eser S, Mathers $C$, Rebelo $M$, et al. Cancer incidence and mortality worldwide: sources, methods and major patterns in GLOBOCAN 2012. Int J Cancer. 2015;136(5):E359-E86.

3.INCA. Instituto do Câncer. Estimativa. Incidência de câncer no Brasil. Rio de Janeiro: Instituto do Cancer; 2008.

4. Templeton AJ, Ace O, McNamara MG, Al-Mubarak M, VeraBadillo FE, Hermanns T, et al. Prognostic role of platelet to lymphocyte ratio in solid tumors: a systematic review and meta-analysis. Cancer Epidemiol Biomarkers Prev. 2014;23(7):1204-12.

5.Grivennikov SI, Greten FR, Karin M. Immunity, inflammation, and cancer. Cell. 2010;140(6):883-99. Doi: $10.1016 /$ j.cell.2010.01.025

6.Leuenberger MI, Kurmann S, Stanga Z. Nutritional screening tools in daily clinical practice: the focus on cancer. Support Care Cancer. 2010;18 Suppl 2:S17-S27. Doi:10.1007/s00520-009-0805-1.

7.Kim KH, Park DJ, Park YS, Ahn SH, Park DJ, Kim HH. Actual 5-Year Nutritional Outcomes of Patients with Gastric Cancer. J Gastric Cancer. 2017;17(2):99-109.

8.Gnagnarella P. Nutrition and cancer: from prevention to nutritional support, 8th October 2010, Milan. Ecancermedicalscience. 2010;4:1-26. Doi: 10.3332/ ecancer.2010.205.

9.Sun K, Chen S, Xu J, Li G, He Y. The prognostic significance of the prognostic nutritional index in cancer: a systematic review and meta-analysis. J Cancer Res Clin Oncol. 2014;140(9):1537-49. Doi: 10.1007/s00432014-1714-3.

10.Schwegler I, von Holzen A, Gutzwiller J-P, Schlumpf R, $M \tilde{A}^{1 / 4 h}$ hlebach S, Stanga Z. Nutritional risk is a clinical predictor of postoperative mortality and morbidity in surgery for colorectal cancer. British J Surg. 2009;97(1):92-7. Doi: 10.1002/bjs.6805.

11. McMillan DC. The systemic inflammation-based Glasgow Prognostic Score: a decade of experience in patients with cancer. Cancer Treat Rev. 2013;39(5):534-40. Doi: 10.1016/j.ctrv.201.08.003.

12.Ahmad J, Grimes N, Farid S, Morris-Stiff G. Inflammatory response related scoring systems in assessing the prognosis of patients with pancreatic ductal adenocarcinoma: a systematic review. Hepatobiliary Pancreatic Dis Int. 2014;13(5):474-81. Doi: 10.1016/ s1499-3872(14)60284-8.

13. Heys SD, Walker LG, Deehan DJ, Eremin OE. Serum albumin: a prognostic indicator in patients with colorectal cancer. J R Coll Surg Edinb. 1998;43(3):163-8.
14.Gupta D, Lis CG. Pretreatment serum albumin as a predictor of cancer survival: a systematic review of the epidemiological literature. Nutrition J. 2010;9(1):69.

15. Wei X-I, Wang F-h, Zhang D-s, Qiu M-z, Ren C, Jin Y, et al. A novel inflammation-based prognostic score in esophageal squamous cell carcinoma: the C-reactive protein/albumin ratio. BMC Cancer. 2015;15(1):1-11.

16.Chen Z, Shao Y, Fan M, Zhuang Q, Wang K, Cao W, et al. Prognostic significance of preoperative $C$-reactive protein: albumin ratio in patients with clear cell renal cell carcinoma. Int J Clin Exp Pathol. 2015;8(11):14893-900.

17.Kinoshita A, Onoda H, Imai N, Iwaku A, Oishi M, Tanaka $\mathrm{K}$, et al. The C-reactive protein/albumin ratio, a novel inflammation-based prognostic score, predicts outcomes in patients with hepatocellular carcinoma. Ann Surg Oncol. 2014;22(3):803-10.

18. Forrest LM, McMillan DC, McArdle CS, Angerson WJ, Dunlop DJ. Evaluation of cumulative prognostic scores based on the systemic inflammatory response in patients with inoperable non-small-cell lung cancer. $\mathrm{Br}$ ] Cancer. 2003;89(6):1028-30.

19.Quyen TC, Angkatavanich J, Thuan TV, Xuan VV, Tuyen LD, Tu DA. Nutrition assessment and its relationship with performance and Glasgow prognostic scores in Vietnamese patients with esophageal cancer. Asia Pac J Clin Nutr. 2017;26(1):49-58.

20. Maurício SF, da Silva JB, Bering T, Correia MITD. Relationship between nutritional status and the Glasgow Prognostic Score in patients with colorectal cancer. Nutrition. 2013;29(4):625-9.

21.Proctor MJ, Morrison DS, Talwar D, Balmer SM, O'Reilly DSJ, Foulis AK, et al. An inflammation-based prognostic score (mGPS) predicts cancer survival independent of tumour site: a Glasgow Inflammation Outcome Study. Br J Cancer. 2011;104(4):726-34.

22.Saijo M, Nakamura K, Masuyama H, Ida N, Haruma $\mathrm{T}$, Kusumoto $\mathrm{T}$, et al. Glasgow prognostic score is a prognosis predictor for patients with endometrial cancer. Eur J Obstet Gynecol Reprod Biol. 2017;210:355-9.

23.Sharma R, Hook J, Kumar M, Gabra H. Evaluation of an inflammation-based prognostic score in patients with advanced ovarian cancer. Eur J Cancer. 2008;44(2):251-6.

24.Guo S, He X, Chen Q, Yang G, Yao K, Dong P, et al. The $\mathrm{C}$-reactive protein/albumin ratio, a validated prognostic score, predicts outcome of surgical renal cell carcinoma patients. BMC Cancer. 2017;17(1):171.

25. Moher D. Preferred reporting items for systematic reviews and meta-analyses: the PRISMA Statement. Ann Int Med. 2009;151(4):264-270.

26. Higgins JPT, Thomas J, Chandler J, Cumpston M, Li $\mathrm{T}$, Page MJ, et al. Cochrane Handbook for Systematic Reviews of Interventions. Haymarket - LD: Cochrane; 2017. $674 \mathrm{p}$.

27.Edge SB, Compton CC. The American Joint Committee on Cancer: the 7th Edition of the AJCC Cancer Staging Manual and the Future of TNM. Ann Surg Oncol. 2010;17(6):1471-4. 
28. Wells GA, Shea B, O'Connel D, Peterson J, Welch V, Losos M, et al. The Newcastle-Ottawa Scale (NOS) for assessing the quality of nonrandomised studies in meta-analyses 2009 [Available from: http://www.ohri. $\mathrm{ca} /$ programs/clinical_epidemiology/oxford.asp.

29. Nyaga VN, Arbyn M, Aerts M. Metaprop: a Stata command to perform meta-analysis of binomial data. Arch Public Health. 2014;72(1):39.

30. Higgins JPT, Thompson SG. Quantifying heterogeneity in a meta-analysis. Stat Med. 2002;21(11):1539-58.

31.DerSimonian R, Laird N. Meta-analysis in clinical trials. Control Clin Trials. 1986;7(3):177-88.

32.Sterne JAC, Sutton AJ, Ioannidis JPA, Terrin N, Jones DR, Lau J, et al. Recommendations for examining and interpreting funnel plot asymmetry in meta-analyses of randomised controlled trials. BMJ. 2011;343:d4002-d.

33. Hwang J-E, Kim H-N, Kim D-E, Choi H-J, Jung S-H, Shim $\mathrm{H}-\mathrm{J}$, et al. Prognostic significance of a systemic inflammatory response in patients receiving first-line palliative chemotherapy for recurred or metastatic gastric cancer. BMC Cancer. 2011;11(1):489.

34. Hwang J-E, Kim H-N, Kim D-E, Shim H-J, Bae W-K, Hwang $\mathrm{E}-\mathrm{C}$, et al. First-line single-agent chemotherapy for patients with recurrent or metastatic gastric cancer with poor performance status. Exp Ther Med. 2012;4(4):562-8.

35.Ishizuka M, Oyama Y, Abe A, Tago K, Tanaka G, Kubota K. Clinical significance of an inflammation-based prognostic system for gastric cancer patients with a preoperative normal serum level of carcinoembryonic antigen. Anticancer Res. 2014;34(12):7219-26.

36. Kubota T, Hiki N, Nunobe S, Kumagai K, Aikou S, Watanabe R, et al. Significance of the inflammationbased Glasgow prognostic score for short- and long-term outcomes after curative resection of gastric cancer. J Gastrointest Surg. 2012;16(11):2037-44.

37.Kunisaki C, Takahashi M, Ono HA, Oshima T, Takagawa $\mathrm{R}$, Kimura J, et al. Inflammation-based prognostic score predicts survival in patients with advanced gastric cancer receiving biweekly docetaxel and s-1 combination chemotherapy. Oncology. 2012;83(4):183-91.

38. Li Q-Q, Lu Z-H, Yang L, Lu M, Zhang X-T, Li J, et al. Neutrophil count and the inflammation-based glasgow prognostic score predict survival in patients with advanced gastric cancer receiving first-line chemotherapy. Asian Pac J Cancer Prev. 2014;15(2):945-50.

39.Liu X, Sun X, Liu J, Kong $P$, Chen S, Zhan $Y$, et al. Preoperative C-Reactive Protein/Albumin Ratio Predicts Prognosis of Patients after Curative Resection for Gastric Cancer. Transl Oncol. 2015;8(4):339-45.

40.Liu X, Chen S, Liu J, Xu D, Li W, Zhan Y, et al. Impact of systemic inflammation on gastric cancer outcomes. PloS ONE. 2017;12(3):e0174085-e.

41. Melling N, Graning A, Tachezy M, Nentwich M, Reeh M, Uzunoglu FG, et al. Glasgow Prognostic Score may be a prognostic index for overall and perioperative survival in gastric cancer without perioperative treatment. Surgery. 2016;159(6):1548-56.

42. Namikawa T, Munekage $E$, Munekage $M$, Maeda $H$, Yatabe $\mathrm{T}$, Kitagawa $\mathrm{H}$, et al. Evaluation of Systemic Inflammatory Response Biomarkers in Patients Receiving Chemotherapy for Unresectable and Recurrent Advanced Gastric Cancer. Oncology. 2016;90(6):321-6.

43. Nozoe T, Iguchi T, Egashira A, Adachi E, Matsukuma A, Ezaki T. Significance of modified Glasgow prognostic score as a useful indicator for prognosis of patients with gastric carcinoma. Am J Surg. 2011;201(2):186-91.

44.Pan Q-X, Su Z-J, Zhang J-H, Wang C-R, Ke S-Y. A comparison of the prognostic value of preoperative inflammation-based scores and TNM stage in patients with gastric cancer. OncoTargets Ther. 2015;8:1375-85.

45.Sachlova M, Majek O, Tucek S. Prognostic value of scores based on malnutrition or systemic inflammatory response in patients with metastatic or recurrent gastric cancer. Nutr Cancer. 2014;66(8):1362-70.

46.Sun X, Wang J, Liu J, Chen S, Liu X. Albumin concentrations plus neutrophil lymphocyte ratios for predicting overall survival after curative resection for gastric cancer. OncoTargets Ther. 2016;9:4661-9.

47. Wang D-s, Ren C, Qiu M-Z, Luo H-Y, Wang Z-q, Zhang $D-S$, et al. Comparison of the prognostic value of various preoperative inflammation-based factors in patients with stage III gastric cancer. Tumour Biol. 2012;33:749-56.

48.Li M-x, Bi X-y, Li Z-y, Huang Z, Han Y, Zhou J-g, et al. Prognostic Role of Glasgow Prognostic Score in Patients With Hepatocellular Carcinoma: A Systematic Review and Meta-Analysis. Medicine. 2015;94(49):e2133-e.

49.Schag CC, Heinrich RL, Ganz PA. Karnofsky performance status revisited: reliability, validity, and guidelines. J Clin Oncol. 1984;2(3):187-93.

50.Polterauer S, Grimm C, Seebacher V, Rahhal J, Tempfer $C$, Reinthaller A, et al. The Inflammation-Based Glasgow Prognostic Score Predicts Survival in Patients With Cervical Cancer. Int J Gynecol Cancer. 2010;20(6):1052-7.

51. Murri AMA, Bartlett JMS, Canney PA, Doughty JC, Wilson C, McMillan DC. Evaluation of an inflammation-based prognostic score (GPS) in patients with metastatic breast cancer. Br J Cancer. 2006;94(2):227-30.

52. Kinoshita A, Onoda H, Imai N, Iwaku A, Oishi M, Tanaka $\mathrm{K}$, et al. The Glasgow Prognostic Score, an inflammation based prognostic score, predicts survival in patients with hepatocellular carcinoma. BMC Cancer. 2013;13(1):13:52.

53. Glen $P$, Jamieson NB, McMillan DC, Carter R, Imrie $\mathrm{CW}$, McKay CJ. Evaluation of an inflammation-based prognostic score in patients with inoperable pancreatic cancer. Pancreatology. 2006;6(5):450-3.

54.Jamieson NB, Mohamed M, Oien KA, Foulis AK, Dickson $E J$, Imrie $C W$, et al. The relationship between tumor inflammatory cell infiltrate and outcome in patients with pancreatic ductal adenocarcinoma. Ann Surg Oncol. 2012;19(11):3581-90. 
55. Richards $\mathrm{CH}$, Roxburgh CSD, MacMillan MT, Isswiasi S, Robertson EG, Guthrie GK, et al. The Relationships between Body Composition and the Systemic Inflammatory Response in Patients with Primary Operable Colorectal Cancer. PloS ONE. 2012;7(8):e41883.

56. Nazha B, Moussaly E, Zaarour M, Weerasinghe C, Azab B. Hypoalbuminemia in colorectal cancer prognosis: Nutritional marker or inflammatory surrogate? World J Gastrointest Surg. 2015;7(12):370-7.

57.Petrelli F, Barni S, Coinu A, Bertocchi P, Borgonovo K, Cabiddu M, et al. The Modified Glasgow Prognostic Score and Survival in Colorectal Cancer: A Pooled Analysis of the Literature. Rev Recent Clin Trials. 2015;10(2):135-41.
58.Lamb GWA, Aitchison M, Ramsey S, Housley SL, McMillan DC. Clinical utility of the Glasgow Prognostic Score in patients undergoing curative nephrectomy for renal clear cell cancer: basis of new prognostic scoring systems. $\mathrm{Br}$ J Cancer. 2011;106(2):279-83.

59.Ramsey S, Lamb GWA, Aitchison M, Graham J, McMillan DC. Evaluation of an inflammation-based prognostic score in patients with metastatic renal cancer. Cancer. 2007;109(2):205-12.

60.Gao Y, Huang D. The value of the systematic inflammation-based Glasgow Prognostic Score in patients with gastric cancer: a literature review. J Cancer Res Ther. 2014;10(4):799-804.

\section{APÊNDICE}

\begin{tabular}{|c|c|c|c|c|c|c|c|c|}
\hline \multicolumn{9}{|c|}{ Newcastle-Ottawa Scale } \\
\hline & & eleção & & Comparabilidade & & Desf & echo & \\
\hline 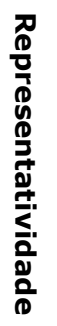 & 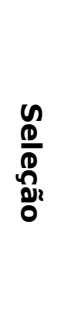 & 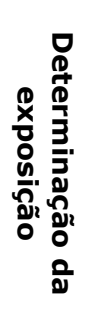 & 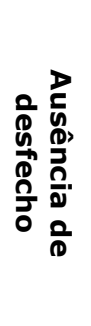 & 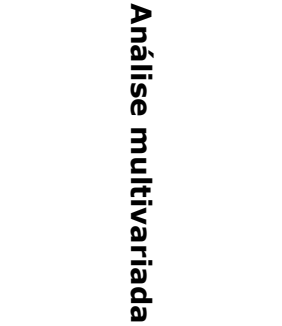 & 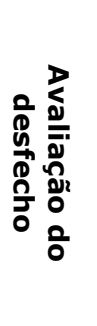 & 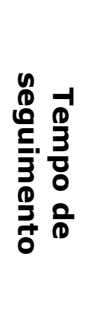 & 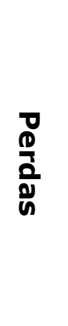 & Total \\
\hline
\end{tabular}

\section{Estudo}

Primeiro autor, ano

\begin{tabular}{|c|c|c|c|c|c|c|c|c|c|}
\hline Hwang, 2011 (33) & 1 & 1 & 1 & 1 & 2 & 1 & 1 & 1 & 9 \\
\hline Hwang, 2012 (34) & 1 & 1 & 1 & 1 & 2 & 1 & 1 & 1 & 9 \\
\hline Ishizuka, 2014 (35) & 1 & 1 & 1 & 1 & 2 & 1 & 1 & 1 & 9 \\
\hline Kubota, 2012 (36) & 1 & 1 & 1 & 1 & 2 & 1 & 1 & 1 & 9 \\
\hline Kunisaki, 2012 (37) & 1 & 1 & 1 & 1 & 0 & 1 & 1 & 0 & 6 \\
\hline $\mathrm{Li}, 2014(38)$ & 1 & 1 & 1 & 1 & 2 & 1 & 1 & 1 & 9 \\
\hline Liu, 2015 (48) & 1 & 1 & 1 & 1 & 1 & 1 & 1 & 1 & 8 \\
\hline Liu, 2017 (40) & 1 & 1 & 1 & 1 & 2 & 1 & 1 & 1 & 9 \\
\hline Melling, 2016 (41) & 0 & 1 & 1 & 1 & 0 & 1 & 1 & 1 & 6 \\
\hline Namikawa, 2016 (42) & 1 & 1 & 1 & 1 & 2 & 1 & 1 & 1 & 9 \\
\hline Nozoe, 2011 (43) & 1 & 1 & 1 & 1 & 1 & 1 & 1 & 1 & 8 \\
\hline Pan, 2015 (44) & 1 & 1 & 1 & 1 & 2 & 1 & 1 & 1 & 9 \\
\hline Sachlova, 2014 (45) & 0 & 1 & 1 & 1 & 2 & 1 & 1 & 1 & 8 \\
\hline Sun, 2016 (46) & 1 & 1 & 1 & 1 & 1 & 0 & 1 & 1 & 7 \\
\hline Wang, 2012 (47) & 1 & 1 & 1 & 1 & 2 & 1 & 1 & 1 & 9 \\
\hline
\end{tabular}

APÊNDICE A. Escala binária de avaliação da Qualidade de Newcastle-Ottawa (NOS), com pontuação de 0 a 9 para os artigos selecionados na revisão sistemática, com base nos critérios de Seleção, Comparabilidade e Desfecho dos estudos.

1: pontuação obtida; 0: Pontuação não obtida; Total: Evidência forte, achados consistentes entre vários estudos de alta qualidade, maior que 7. 


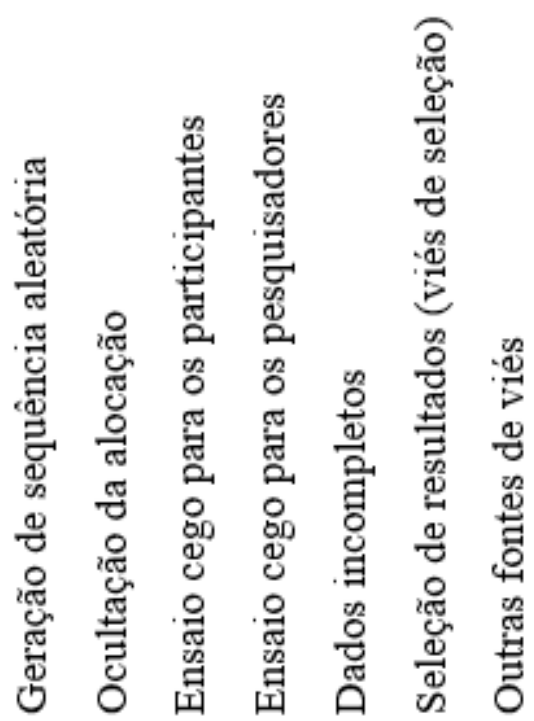

Hwang, 2011 (33)

Hwang, 2012 (34)

Ishizuka, 2014 (35)

Kubota, 2012 (36)

Kunisaki, 2012 (37)

Li, 2014 (38)

Liu, 2015 (39)

Liu, 2017 (40)

Melling, 2016 (41)

Namikawa, 2016 (42)

Nozoe, 2011 (43)

Pan, 2015 (44)

Sachlova, 2014 (45)

Sun, 2016 (46)

Wang, 2012 (47)

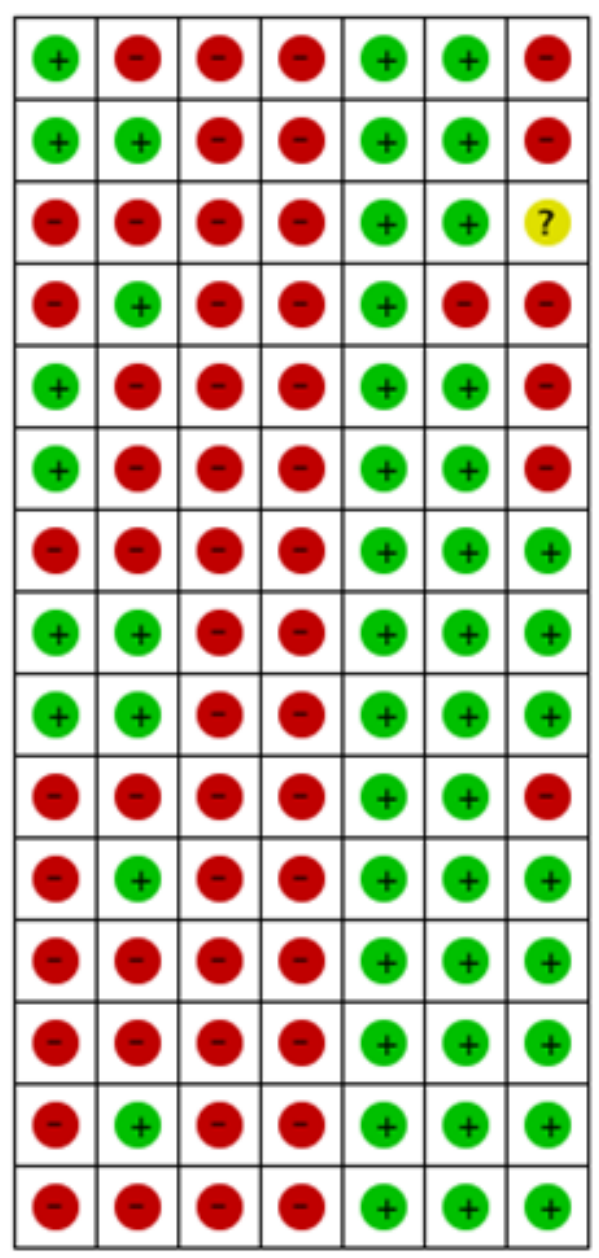

APÊNDICE B. Avaliação do risco de viés dos estudos incluídos na revisão sistemática.

Legenda: Vermelho: alto risco; Verde: baixo risco; Amarelo: risco desconhecido com base em características metodológicas dos estudos, conforme a ferramenta da Cochrane Collaboration. 
Autor Correspondente:

Gerson Suguiyama Nakajima

ganakajima@gmail.com

Apoio: Fundação de Amparo à Pesquisa do Estado do Amazonas (FAPEAM)

Editor:

Prof. Dr. Paulo Henrique Manso

Recebido: 08/09/2020

Aprovado: 29/05/2021 